\title{
Preserving the Cultural Heritage of Afghanistan
}

\section{(C) UNESCO}

Afghanistan Centre at Kabul University (Kabul, Afghanistan) - November 9-11, 2014

On the 9th November Paolo Fontani, Director and Country Representative for UNESCO Kabul office gave a key note speech at the opening sessions for a series of workshops with the theme, 'Preserving the Cultural Heritage of Afghanistan'. Mr. Fontani spoke on the topic "Meeting the Challenges of the Past, Present and Future: Towards Safeguarding the Cultural Heritage of Afghanistan" in the session on 'Organizational Frameworks, alongside Deputy Minister SayedKhalili and Laura Tedesco, representative from the U.S. Department of State.

Mr. Fontani stressed the nature of the current critical development challenges facing the country and how this can negatively affect the sustained impetus required for the long-term rehabilitation of Afghan cultural heritage, and any associated socio-economic development. He emphasized the absolute significance of the contribution culture can make towards broader development goals within the country, including local and regional employment, income generation, education and the promotion of a cohesive society within the all-embracing context of promoting peace and nation building, drawing specifically on examples from UNESCO's forthcoming programmes in Bamiyan and Herat. MrFontani also reiterated the importance of promoting positive public discussion to promote inter-cultural understanding at both provincial and national level.

He also highlighted UNESCO's long term partnership with the Afghan Government working in the cultural heritage sector throughout Afghanistan. Mr. Fontani gave a brief overview of UNESCO's current programmes in the country including the forthcoming Bamiyan Cultural Centre funded by the Government of Korea (with the online design competition to go live on the 15th November), Italian government funded programmes in Bamiyan and at the Timurid mausoleum of Gowhar Shad in Herat, proposed strategies for stabilization works in the west Buddha niche and emergency consolidation works at the Ghurid period Minaret of Jam, and the recently instigated project concerning Cultural Heritage and the Extractive Industries.

Mr. Fontani concluded with the remarks that considerable international assistance is still required to assist in safeguarding the cultural heritage of the country, and will be for another generation or more, specifically in terms of capacity building and financial assistance. This is, however, viewed against a backdrop of decreasing donor funding generally (even more so in the cultural sector), and the fact that funding alone will not necessarily resolve the current issues experienced by the heritage community in Afghanistan. Therefore, the challenge for the new Afghan government in particular, and those organizations working with it, is not only to raise awareness of the greater role that culture can play in peace and development, but also to be progressively more innovative in their joint approaches to incorporate culture into both policy and broader development projects. 
The introductory session was also privileged to receive a live, personal phone call (broadcast to the delegates) from the newly inaugurated President, H.E. Ashraf Ghani, who spoke concerning the great importance of the work the Afghan cultural sector and international partners are undertaking to document and preserve the country's wealth of historical monuments and ancient artefacts, along with the more intangible aspects of the nation's heritage. He concluded by asking all those involved in the cultural heritage sector in Afghanistan to coordinate and cooperate on new initiatives and bring forward any ideas to him, which he assured would receive his utmost attention and support.

The series of workshops, which ran from the 9th - 11th November, was officially opened by His Excellency SayedMakhdoomRaheen (Acting Minister for Information and Culture), hosted by the Afghan Centre at Kabul University (ACKU) and organised by the Chicago Institute for Oriental Studies whom are currently in the final stages of a two year programme to digitally record the National Museum of Afghanistan's existing paper archive. The workshops brought together a wide range of Afghan and international specialists from the ministry departments, museums, international organizations and research institutes with the objective of assessing the current state of the efforts to preserve cultural heritage in Afghanistan and future prospects in this area.

The papers focused on both ongoing and recently completed heritage projects throughout the provinces, specifically what is being implemented by numerous stakeholders to document, restore and preserve a number of historic monuments, build capacity in the museums, address aspects of crossborder illicit trafficking and to recognise elements of the country's rich intangible heritage, often neglected. It is hoped that the results from the workshops and discussions held over the three days will assist the heritage community in identifying specific factors that might determine the success, failure and sustainability of future heritage projects in Afghanistan.

Representatives from the culture unit in the Kabul office were able to attend a number of the workshops with Sara Noshadi (Project officer, Kabul), also acting as moderator for the session on education and intangible cultural heritage, and Mr. Bert Praxenthaler (contractor for UNESCO and ICOMOS), giving a presentation on "Traditional Techniques and Materials on the Conservation Projects at Bamiyan", as part of the ongoing Italian funded programme of stabilization and restoration at Shar-e Gholghola, the 12th century citadel in central Bamiyan. Other workshop themes included 'The Role of Museums in Cultural Heritage Preservation', 'Preserving the Monuments of Afghanistan' and 'Looting and Repatriation of (Historic) Objects'.

The workshops closed with a key note speech by J. Leslie (Board of Directors of the Afghan Conservation $\mathrm{NGO}, \mathrm{ACCHO}$ ), who spoke on the varying degrees of success of heritage initiatives in Afghanistan, and how these might be improved upon in the future.

Conclusions and any recommendations from the workshops are due to be published early in 2015 in English and Dari, with a free downloadable PDF of the proceedings also available. 